\title{
1 A multidisciplinary investigation into "playing-up" in academy football 2 according to age phase
}

In an attempt to facilitate more appropriate levels of challenge, a common practice in academy football is to play-up talented youth players with chronologically older peers. However, the context of playing-up in academy football is yet to be empirically explored. Thus, the purpose of this study was to examine the multidimensional factors that differentiated players who play-up from those who do not. Ninety-eight participants from a single football academy were examined within their age phase: Foundation Development Phase (FDP; under-9 to under-11; $n=40$ ) and Youth Development Phase (YDP; under-12 to under-16; $n=58$ ). Drawing upon the FA Four Corner Model, 27 factors relating to Technical/Tactical, Physical, Psychological, and Social development were assessed. Following MANOVA analysis within both the FDP and YDP, significant differences were observed for Technical/Tactical and Social subcomponents $(P<0.05)$. Further differences were observed for Physical and Psychological sub-components $(P<0.05)$ within the YDP. In sum, Technical/Tactical and Social characteristics appeared to differentiate those who play-up compared to those who do not within the FDP. In the YDP however, there were measures representing all sub-components from the FA Four Corner Model. Subsequently, it is suggested coaches and practitioners consider these holistic factors when playing-up youth football players within relevant age-phases.

Keywords: Accelerated learning; Elite youth football; Expertise; Talent identification; Talent development; Relative age effect 


\section{Introduction}

24 A key challenge for sport organisations relates to creating appropriate developmental settings for athletes (Côté, Turnnidge, \& Evans, 2014). Indeed, understanding how to effectively meet the needs of athletes with a varying range of experience, ability, and motivation is a perpetual struggle for sport practitioners (Côté, Bruner, Erickson, Strachan, \& Fraser-Thomas, 2010). In general, the typical method for grouping athletes is by chronological age. However, within these age-bands, there may be large discrepancies in athletes' physical and psychosocial development (Wattie \& Baker, 2018). For high-achieving athletes, there is often pressure from stakeholders (e.g., organisations, coaches, and parents) to search for more appropriate levels of challenge and competition (Collins \& MacNamara, 2017; Taylor \& Collins, 2019). One common solution to this issue is for athletes to train and compete with older peers; this practice is commonly known as playing-up (Malina et al., 2019). Anecdotal evidence suggests that athletes who play-up may be exposed to higher intensities of practice and competition, which could have important implications on their developmental outcomes (e.g., Malina, 2010; O’Sullivan, 2017; U.S. Soccer, 2011; Wiersma, 2000). However, no studies to date have explored playing-up a chronological age group and its connections to athletes' outcomes.

If playing-up is thought of as a way to group athletes based on skill, there is a growing body of research on how other forms of athlete grouping may affect development. Current literature in sport has mainly explored the effects of grouping athletes based on chronological age and size. With regards to chronological age, concerns have been raised due to relative age effects (RAEs) that favours older athletes in a respective age group (Barnsley, Thompson, \& Barnsley, 1985). For instance, when sport programmes create age groups using an annual calendar year, athletes born just after the cut-off date are older than most of their peers

47 (Musch \& Grondin, 2001). As such, these athletes are often bigger and stronger than those 
born later in the selection year, and fortuitously size and strength are often mistaken or misconstrued as implications of talent (Baker, Schorer, \& Wattie, 2018; Baxter-Jones, 1995;

Cobley, Baker, Wattie, \& McKenna, 2009). To be specific, if the oldest athletes are chosen

for a competitive team because of their age or physical qualities, they may gain access to quality coaching, competition, and facilities, which could allow them to become better players (e.g., Furley \& Memmert, 2016; Sherar, Baxter-Jones, Faulkner, \& Russell, 2007; Wattie, Cobley, \& Baker, 2008). Conversely, studies have shown detrimental effects for relatively younger athletes, including limited selection opportunities and higher rates of dropout (e.g., Delorme, Chalabaev, \& Raspaud, 2011; Hancock, Ste-Marie, \& Young, 2013; Helsen, Starkes, \& Van Winckel, 1998). It is also important to consider that RAEs also go "beyond the physical", whereby age related differences in experience, cognitive, and social development can exacerbate relative age advantages (Doncaster, Medina, Drobnic, GómezDíaz, \& Unnithan, 2020). Together, these findings indicate that when youth athletes are grouped based on fixed chronological age, there are important implications for athlete development.

Further to the bias of an earlier birthdate through RAEs, differences in growth and maturation status within a single age group can also be considerable (Pearson, Naughton, \& Torode, 2006). Indeed, it is important to recognise that RAEs and maturation are independent constructs (Cumming, Searle, et al., 2018). For instance, within an under-13 chronological age group, it is possible to have two players with the same relative age but as much as five years difference in biological age (Gouvea et al., 2016; Malina, Rogol, Cumming, Coelho-eSilva, \& Figueiredo, 2015). Thus, individual increases in physical performance, such as speed, power, agility, and endurance, will also occur at different chronological ages (Lloyd \& Oliver, 2012). Therefore, a player's earlier growth and maturity status, relative to their latermaturing but same-aged peers, may possess advantages in both physiological and physical 
performance measures (Meylan, Cronin, Oliver, \& Hughes, 2010). As a result, this often leads to systematic selection and progression of more mature players compared to less mature counterparts, who may be regarded as less talented during the player selection process, or dropout due to low confidence or lack of success (Figueiredo, Goncalves, Coelho-e-Silva, \& Malina, 2009).

Drawing upon an education context, in the same way that coaches can play-up talented youth athletes to expose them to a greater intensity of practice and competition, teachers can move high-achieving students into advanced streams of study; providing them with learning opportunities that are more appropriately challenging (e.g., Kulik, 2004; Neihart, 2007; Tieso, 2005; Vygotsky, 1978). For example, acceleration (i.e., when students enter school early or skip a grade) is a strategy that is comparable to playing-up. Previous research on the impact of acceleration on youth's academic achievement has often supported its implementation (Steenbergen-Hu, Makel, \& Olszewski-Kubilius, 2016). Meta-analytic data from Kulik and Kulik (1982) and Steenbergen-Hu and Moon (2011) found that highachieving students who were accelerated showed greater academic performance than their non-accelerated equivalents, whilst also matching similar academic attainment to that of their older peers. This evidence suggests the movement of youth into advanced learning environments may be associated with positive performance outcomes for high-achieving individuals. However, without advanced knowledge regarding how and why acceleration in school and sport may affect academic achievement and sport-specific development, practitioners will struggle to optimise programming for high-achieving students and athletes alike. Therefore, in the context of playing-up, it is necessary to examine the factors that influence the sport-specific development of those particular athletes.

To improve this understanding, recent research has developed tools to assess multiple aspects of athlete development (e.g., Kelly, Wilson, \& Williams, 2018). More specifically in 
football, there has been a growing body of multidisciplinary athlete development research in recent years, with evidence showcasing how certain factors are associated with greater development towards attaining expertise (see Sarmento, Anguera, Pereira, \& Araujo, 2018).

For example, Forsman, Blomqvist, Davids, Liukkonen, and Konttinen (2016), Huijgen, Elferink-Gemser, Lemmink, and Visscher (2014), and Zuber, Zibung, and Conzelmann (2016) all applied a battery of holistic tools to measure athlete development in youth football. They all revealed that highly skilled players scored above average on all physiological, psychological, tactical, and technical factors compared to their lower skilled peers, as well as being more likely to advance to the highest level of performance. This highlights the importance of providing a multidisciplinary research methodology in youth football for athlete development (Collins \& MacNamara, 2017; Williams \& Drust, 2012). Multidisciplinary philosophies are evident through applied frameworks such as the FA Four Corner Model (The Football Association, 2019). This model, which is often adopted in professional football clubs and organisations, advocates the assessment and development of players according to: (a) Technical/Tactical, (b) Physical, (c) Psychological, and (d) Social attributes (The Football Association, 2014). Previous observational investigation from Towlson, Cope, Perry, Court, and Levett (2019) has demonstrated the usefulness of applying the FA Four Corner Model to holistic research in academy football. This study also reinforces the importance of encompassing an age phase-specific approach to applied athlete development literature. Additionally, by using this model to facilitate a greater knowledge translation between theory and practice, it provides a salient framework for understanding the factors associated with playing-up since it is a tool that is perceived to be relevant and useful for sport practitioners.

Therefore, the purpose of this study was to examine the multidimensional factors that differentiated players who play-up a chronological age group, compared to those who do not, 
123 within an English football academy according to age phase (FDP and YDP). It was

124 hypothesised that characteristics across the FA Four Corner Model would positively

125 differentiate between those players who play-up and those who do not within both age

126 phases.

\section{Methods}

\section{Sample}

129 Following institutional ethical approval and informed consent, ninety-eight male participants

130 were examined within their specific age phase: FDP (under-9 to under- $11 ; n=40 ; M_{\text {age }} 10.6$

$131 \pm 0.9$ years) and YDP (under-12 to under- $16 ; n=58 ; M_{\text {age }} 14.4 \pm 1.3$ years). All the

132 participants were recruited from the same Tier 4 English professional football club and their

133 Category 3 academy. Players were considered to play-up a chronological age group when

134 they participated in $\geq 50 \%$ of their combined training and match-play time, throughout the

135 entire season, within an older age group in the FDP ( $n=15$ play-up; $n=25$ non-play-up) and

136 YDP ( $n=13$ play-up; $n=45$ non-play-up). Previous playing-up experience was also recorded

137 for the playing-up groups across the two age phases: (a) FDP play-up experience ranged from

138 1-4 years $\left(M_{\text {play-up }}=2 \pm 0.9\right.$ years $)$; and, (b) YDP play-up experience ranged from 2-8 years

139 ( $M_{\text {play-up }}=4.6 \pm 2.4$ years $)$. The average weekly training and match-play time was also

140 recorded for both age phases: (a) FDP = 9-10.5 training hours/week and one match-play

141 hour/week; and, (b) YDP = 10-14.5 training hours/week and one match-play hour/week.

142 Goalkeepers were not included in this study due to their contrasting position-specific

143 requirements (Gil et al., 2014). Institutional ethical approval was granted for this study.

\section{Measures}

145 Seven data collection methods were measured across an entire football season. For the 
146 purpose of this research, these measures were then allocated into sub-components, in-line with the FA Four Corner Model: (1) Technical/Tactical; (a) technical tests, (b) match analysis statistics, and (c) perceptual-cognitive expertise (PCE) video simulation tests. (2) Physical; (a) anthropometric measures, and (b) fitness tests. (3) Psychological; (a) the Psychological

150 Characteristics for Developing Excellence Questionnaire (PCDEQ). And, (4) Social;

151 Participation History Questionnaire (PHQ). The citation(s) aligned to each measure(s) below represents the instrument and protocol used for the factors in this current study. football-specific technical tests; (a) ball juggling, (b) slalom dribble, (c) shooting accuracy, and (d) lob pass (see Vaeyens et al., 2006). (2) Four match analysis statistics from across an entire season; (a) reliability in possession, (b) pass completion, (c) dribble completion, and (d) total touches (see Kelly, Wilson, Jackson, \& Williams, 2020). (3) Two PCE video simulation tests; (a) 'pre' execution occlusion, and (b) 'at' execution occlusion (see Belling, Suss, \& Ward, 2014). (4) All six factors from the 59-item PCDEQ; (a) Factor 1 - support for

160 long term success, (b) Factor 2 - imagery use during practice and competition, (c) Factor 3 161 coping with performance and developmental pressures, (d) Factor 4 - ability to organise and engage in quality, (e) Factor 5 - evaluating performances and working on weaknesses, and (f) Factor 6 - support from others to compete to my potential (see MacNamara \& Collins, 2011; 2013). (5) Six items from the PHQ; (a) age started playing academy football, (b) total coach-

165 led practice hours, (c) total peer-led play hours, (d) total football hours, (e) total multisport 166 hours, and (f) total football and multisport hours (see Ford, Ward, Williams, \& Hodges, 167 2009). (6) One anthropometric measure; (a) percentage of estimated adult height attained (see 168 Khamis \& Roche, 1994). And, (7) Four fitness tests; (a) 0-10 m sprint test, (b) 0-30 m sprint 169 test, (c) L-agility test, and (d) countermovement jump (CMJ) test (see Kelly, Wilson, 170 Jackson, Turnnidge, \& Williams, 2020). 


\section{Data analysis}

172 Descriptive statistics were calculated for each variable using $z$-scores to account for

173 differences between chronological ages in each age phase, as well as confirming with data

174 normality. Four separate hypotheses were tested to examine the differences between playing-

175 up and non-playing-up groups, within each age phase, corresponding to the FA Four Corner

176 Model. Initial analysis investigated differences between playing-up and non-playing-up

177 groups' mean scores within both age phases using a two-way multivariate analysis of

178 variance (MANOVA). Further analysis used an independent samples $t$-test to compare

179 playing-up and non-playing-up groups' mean scores within both age phases, with a

180 Bonferroni correction applied to prevent alpha inflation. Cohen's $d$ effect size was used to

181 examine the magnitude of difference between those who play-up and those who do not, with

$182 d=0.2,0.5$, and 0.8 marking small, medium, and large effect sizes, respectively. A binary

183 logistic regression was also used to model playing-up and non-playing-up status within both

184 age phases, comprising of univariate analysis from the variables within each of the four sub-

185 components. Further multivariate logistic regression analysis was conducted for both the FDP

186 and YDP, with variables included when significant or nearing significance $(P<0.100)$ in the

187 univariate analyses which accumulated all the four corners. The multivariate model employed

188 a backward stepwise elimination of variables. Differences were considered statistically

189 significant at $P<0.05$.

$190 \quad$ Results

191 MANOVA of between group differences

192 The MANOVA for the Technical/Tactical sub-component showed a significant between

193 group difference within both the FDP, F(10,29) $=6.044, P<0.001$ with Pillais' Trace =

1940.676 , and the YDP, $\mathrm{F}(10,46)=2.088, P=0.045$ with Pillais' Trace $=0.312$. The 
195 MANOVA for the Physical sub-component showed no significant between group difference

196 within the FDP, $\mathrm{F}(5,34)=2.968, P=0.096$ with Pillais' Trace $=0.232$. However, there was a

197 significant between group difference for the Physical sub-component within the YDP,

$198 \mathrm{~F}(5,51)=3.766, P=0.006$ with Pillais' Trace $=0.270$. The MANOVA for the Psychological

199 sub-component showed no significant between group difference within the FDP, F(6,33)=

$2000.583, P=0.741$ with Pillais' Trace $=0.096$. However, there was a significant between group

201 difference for the Psychological sub-component within the YDP, F(6,50) $=4.160, P=0.002$

202 with Pillais' Trace $=0.333$. The MANOVA for the Social sub-component showed a

203 significant between group difference within both the FDP, $\mathrm{F}(6,33)=2.560, P=0.038$ with

204 Pillais' Trace $=0.318$, and the YDP, $\mathrm{F}(6,50)=2.493, P=0.035$ with Pillais' Trace $=0.230$.

\section{Technical/Tactical}

206 Within the FDP, there was a significant difference between the playing-up and non-playing-

207 up groups, with the playing-up group recording a greater pass completion, lob pass, and PCE

208 'pre'. Within the YDP, there was a significant difference between the playing-up and non-

209 playing-up groups, with the playing-up group recording greater total touches. A Bonferroni

210 correction was applied, with results considered significant at $P<0.005$ (see Table 1).

\section{Physical}

213 Within the FDP, there were no significant differences between the playing-up and non-

214 playing-up groups. Within the YDP, there was a significant difference between the playing-

215 up and non-playing-up groups, with the playing-up group recording greater percentage of

216 estimated adult height attained and CMJ height, as well as quicker $0-10 \mathrm{~m}$ and $0-30 \mathrm{~m}$ sprint times. A Bonferroni correction was applied, with results considered significant at $P<0.01$ 


\section{Psychological}

221 Within the FDP and YDP, there were no significant differences between the playing-up and

222 non-playing-up groups. A Bonferroni correction was applied, with results considered significant at $P<0.008$ (see Table 3).

$* * * *$ Table 3 near here****

\section{Social}

Within the FDP, there was a significant difference between the playing-up and non-playingup groups, with the playing-up group recording greater total football and multisport hours. Within the YDP, there was a significant difference between the playing-up and non-playingup groups, with the playing-up group recording greater total coach-led practice hours. A

230 Bonferroni correction was applied, with results considered significant at $P<0.008$ (see Table 4).

\section{Multivariate analysis}

234 Within the FDP, the multivariate logistic regression across the four corners showed a significant association with playing-up $\left(\chi^{2}(4)=38.486, P<0.001\right)$, with the lob pass and PCE 'pre' significant predictors within the model and accounted for $61.8 \%$ of variance observed. Within the YDP, the multivariate logistic regression across the four corners showed a significant association with playing up $\left(\chi^{2}(4)=39.610, P<0.001\right)$, with ball juggle, $0-10$ m sprint, PCDEQ Factor 3, PCDEQ Factor 6, and total coach-led practice hours significant 
predictors within the model and accounted for $49.5 \%$ of variance observed (see Table 5).

\section{Discussion}

243 Through adopting a holistic practical framework, the primary aim of this study was to

244 examine the characteristics that discriminated academy football players who played-up a chronological age group compared to those who did not. By employing the FA Four Corner Model, it was found that the majority of the significant factors associated with playing-up within the FDP were Technical/Tactical and Social in nature. In comparison, results within the YDP revealed measures representing a broader multidisciplinary perspective. The wider range of differences observed within in the YDP group may be due to the fact that these older players benefited from more years of playing-up and accumulated more training. As such, the implications of these findings provide an impetus for coaches and practitioners to reflect upon when considering playing youth football players up a chronological age group according to age phase.

Technical features, including greater reliability in possession and pass completion, have been associated with superior performance outcomes at senior professional level (e.g., Gomez, Mitrotasios, Armatas, \& Lago-Penas, 2018; Liu, Hopkins, \& Gomez, 2016; 2018). Athlete development literature in youth football has also cited technical abilities as

259 distinct predictors of greater developmental outcomes (Figueiredo, Coelho-e-Silva, \& Malina, 2011; Figueiredo et al., 2009). In this current study, Technical/Tactical factors appeared to be

261 discriminant functions for playing-up amongst both age phases. However, there were no

262 common themes between the age phases regarding specific Technical/Tactical characteristics.

263 There appears to be an association between a greater ball maintenance and executing accurate 
actions with playing-up in the FDP (i.e., reliability in possession, pass completion, shooting accuracy, and lob pass). Whereas, in the YDP, more creative skills appeared to be associated with playing-up (i.e., dribble completion, total touches, slalom dribble, and ball juggling). Thus, the complex nature of the age-specific developmental process coupled with the technique-specific demands of the modern game are important considerations in the playingup decision-making process for coaches and practitioners. There are a number of potential reasons why Technical/Tactical factors differentiated those who play-up compared to those who do not. First, since coaches are often the decisionmakers in the playing-up process and have a greater understanding of Technical/Tactical

273 features compared to the other sub-components (Lefebvre, Evans, Turnnidge, Gainforth, \& 274 Côté, 2016); greater value may be placed on these characteristics compared to the others. Indeed, the term "if you are good enough, you are old enough" is commonly used to make reference towards technical ability driving the decision for a player to compete in an older age group, thus placing an important emphasis on creating a developmentally appropriate environment beyond chronological age grouping. Furthermore, from a positive youth development perspective, traditional coach education and sport-specific qualifications often focus on athlete competence compared to other developmental factors (e.g., confidence, connection, and character; Côté et al., 2010; Fraser-Thomas et al., 2005; Lefebvre et al., 2016). Thus, whilst more evidence is required, it is suggested coaches and organisations involve key stakeholders (e.g., Sport Scientists, Sport Psychologists, Strength and

284 Conditioning Coaches) as part of a broader, multidimensional decision-making strategy when considering to play a young athlete up an age group (Piggott, Müller, Chivers, Papaluca, \& Hoyne, 2019).

It is well acknowledged that the observation of physical characteristics is an important part of the talent identification and development processes in youth football (Kelly \& 
289 Williams, 2020). In the context of playing-up, this current study revealed the 0-30 m sprint

290 test was a key discriminator in both age phases, suggesting that it is an efficient physical test.

291 It is also worth recognising previous football development literature has acknowledged sprint

292 ability as a contributing factor towards an increased likelihood of recruitment (Carling, Le

293 Gall, \& Malina, 2012), greater developmental outcomes (Buchheit \& Mendez-Villanueva,

294 2014; Gonaus \& Müller, 2012), and attaining senior professional status (Le Gall, Carling,

295 Williams, \& Reilly, 2010). Findings within the YDP also exemplify how further fitness testing factors (i.e., 0-10 m sprint test and CMJ), alongside enhanced maturity status (greater

297 percentage of estimated adult height attained), contributed to playing-up. Perhaps this can be

298 recognised as a positive outcome, whereby coaches and practitioners are (consciously or

299 unconsciously) identifying enhanced physical performance and maturity status in certain

300 players, and thus offering them the opportunity to play-up to counteract or moderate their

301 physical presence within their respective chronological age group (Baxter-Jones, 1995).

302 Conversely, if coaches and practitioners are mistaking athletes' maturity for their ability, this

303 may negatively affect the long-term developmental outcomes of late maturing athletes; who

304 might miss the opportunity for more appropriate levels of competition and coaching through

305 playing-up (Cobley et al., 2009). Due to the quantitative nature of this current study, one

306 difficulty is being unable to directly identify how much a decision of playing-up is based on a

307 reward for outperforming age group peers, and how much a decision is based on providing

308 sufficient challenge. Therefore, further research is needed to understand coaches and

309 practitioners' rationale for selecting youth athletes to play-up, and how this may influence

310 their development through playing-up.

311 To mitigate growth and maturation advantages that encompass chronological age

312 grouping, bio-banding (i.e., grouping athletes based on biological age) has been introduced in

313 team sports (Bradley et al., 2019; Cumming, Lloyd, Oliver, Eisenmann, \& Malina, 2017). 
314 Proponents of bio-banding suggest that it may help to reduce inequality in competition that

315 occurs due to growth and maturation differences between same-aged athletes (Malina et al.,

316 2015). Specifically, when athletes with larger body types compete against each other, they

317 have been shown to rely less on their size and more on their skill to succeed (Cumming,

318 Brown, et al., 2018). At the same time, when athletes with smaller body types compete

319 against each other, they may be exposed to more manageable levels of challenge (Bradley et

320 al., 2019; Malina et al., 2015). Thus, when applied to the context of playing-up, for those

321 with advanced maturity status and physical performance characteristics in the YDP, playing-

322 up may also be a useful tool to moderate these Physical advantages. Furthermore, it is

323 necessary to critique current knowledge regarding the needs of youth athletes who compete

324 above their age level, and the differentiating factors that allow these athletes to succeed under

325 challenging circumstances.

326 Although birth quarter was not included in the initial data analysis, it was found that

32714 out of the 15 players who played-up in the FDP were born in the first half of the year.

328 Additionally, nine out of 13 of the players who played-up in the YDP were born in the first

329 half of the year. As a result, the overrepresentation of early birth quartiles who play-up

330 should not be ignored. As such, it may be suggested playing-up can impact upon

331 chronological age group development twofold: (a) playing-up may moderate the RAE by

332 presenting a new cohort of later birth quartiles. This proposal would enable players who play-

333 up to become the youngest in the older age group they move into. And, (b) playing-up may

334 create an underdog effect (e.g., Gibbs, Jarvis, \& Dufur, 2012) for chronologically older

335 players. This psychologically based explanation suggests playing-up may facilitate long-term

336 developmental outcomes by necessitating players to overcome the odds of the RAE through

337 being challenged by older and more advanced peers (Kelly et al., 2020). 

related to sport psychology and youth football (Gledhill, Harwood, \& Forsdyke, 2017). Psychological factors in this current study revealed the PCDEQ Factor 6 (support from others to compete to my potential) was greater in those who played-up in the YDP. Perhaps this is a result of playing-up being recognised as a reward from coaches or practitioners for expert age group performance (resulting in greater perceived support; Ginsburg, 2014; O’Sullivan, 2017); as opposed to acknowledging it as a tool to facilitate development. Alongside the importance of the coach-athlete relationship, previous research has demonstrated the particular importance of support from parents to facilitate long-term player development in

347 football. For instance, Kavussanu, White, Jowett, and England (2011) found elite-level

348 football players often have parents who create an environment of appreciation of success through hard work and learning. Consequently, this may support the athlete development process in youth football through player-level task-oriented and self-determined motivation, which is associated with a supportive parenting environment (Ullrich-French \& Smith, 2009). Moreover, this may also develop a culture of unconditional self-acceptance and an increased self-awareness in youth football players, which could be required whilst fluctuating between chronological age groups (Hill, Hall, Appleton, \& Kozub, 2008). moving players up an age group, such as: (a) recognise they are being taken away from their chronological age group friends (Bradley et al., 2019). (b) Appreciate they are changing their age group coach and realise that their individual needs may change (Renshaw, Oldham, \& Bawden, 2012). (c) Psychological and behavioural support should be offered to help them compete against older players (e.g., Vygotsky, 1978). And, (d) ensure they (and their parents)

361 are being supported during this transition (Harwood, Drew, \& Knight, 2016). Thus, this

362 process must be carefully considered by all key stakeholders (e.g., coaches, practitioners, 
players, and parents) to protect the individual's psychological well-being. Indeed, in the context of playing-up, Vygotsky (1978) suggests that the role of a coach is to skilfully facilitate a child's development by sharing knowledge, as well as controlling those elements of a task that are initially beyond the player's capabilities. Overall, contrary to Towlson et al. (2019) who highlighted that practitioners placed significantly greater perceived importance on psychological factors compared to the other three sub-components, this current research suggests it may be more beneficial to focus on psychology as one aspect as part of a holistic approach to athlete development. Nevertheless, further qualitative research is required to understand the personal experiences of athletes who play-up, as well as the decision-making processes of their coaches. engagement, have attempted to align activities to developmental pathways for youth athletes', in order to maximise their potential to achieve senior expertise (e.g., Côté, Baker, \& Abernethy, 2007; Côté, Turnnidge, \& Vierimaa, 2016; Ericsson, Krampe, \& Tesch-Roemer, 1993; Ford \& Williams, 2017; Ford et al., 2009). In football specifically, existing research appears mixed, in that each of the activity types are associated with development and performance outcomes in some but not in others. For instance, sport-specific peer-led play and coach-led practice in football is typically associated with performance at both youth and senior level (Hendry \& Hodges, 2018; Hendry, Williams, \& Hodges, 2018; Roca, Williams,

$382 \&$ Ford, 2012). In contrast, engagement in multisport activities during childhood and

383 adolescence appeared to be the biggest performance discriminator for greater senior age performance (Güllich, 2019; Güllich, Kovar, Zart, \& Reimann, 2016; Hornig, Aust, \& Güllich, 2016). This current study proposes it is not necessarily the type of activity, but more specifically the quantity of engagement through a diverse range of activities that contributes to playing-up. In the FDP for instance, total football and multisport hours was the only Social 
factor associated with playing-up. In comparison, total coach-led practice hours and total peer-led play hours were associated with playing-up in the YDP.

demonstrate an increased self-determined motivation to achieve expertise (Hendry, Crocker,

392 Williams, \& Hodges, 2019) or a greater vested interest in football activity (Memmert, Baker,

$393 \&$ Bertsch, 2010). It may also be suggested that engaging in a greater amount of coach-led practice, peer-led play, and multisport activity together are all contributing factors to superior development. Coaches and practitioners are encouraged to incorporate an array of activities within a football academy setting (e.g., multisport games, child-led sessions) to offer a broader range of development opportunities. Since the Social elements within this particular study only focussed on the environment that athletes develop through exploring their sport participation history (e.g., coach-led practice, peer-led play, individual practice, competition, multisport activities), it is also important to recognise the need for more broader social measures in athlete development literature in future playing-up research (e.g., social identity,

402 Bruner \& Benson, 2018; prosocial behaviour, Kavussanu \& Boardley, 2009; moral

403 disengagement, Boardley \& Kavussanu, 2007). As such, these research methodologies may prove fruitful in guiding a social-specific component as part of a greater holistic approach.

\section{Limitations and future directions}

406 It is important to consider methodological limitations inherent with observational case 407 studies, such as access to limited participants and issues with external validity (Morgan, 408 Pullon, Macdonald, McKinlay, \& Gray, 2017). To address these limitations, it is important to 409 recognise the accessibility to a sample of professional football academy players that are often 410 difficult to recruit, particularly for multidisciplinary observations. Thus, the methodological 411 framework applied to this current study offers a holistic resource to reflect upon when 
412 considering playing young football players up a chronological age group according to age

413 phase. Regarding the potential concern of applying these findings externally, the category

414 status and geodemographic factors that distinguish academies must be considered. Thus, it is

415 important to recognise this study recruited Category 3 academy players from the South West

416 of England, and whether findings can be applied to higher-level category academies or other

417 countries remains unclear.

418 Although playing-up has implications for performance and developmental outcomes

419 in youth football, further qualitative research is required to investigate athlete perceptions and 420 experiences of playing-up (e.g., Goldman, Turnnidge, Kelly, de Vos, \& Côté, under review).

421 Parents perceive playing-up as an opportunity for young players to attain positive

422 performance outcomes (Ginsburg, 2014; O’Sullivan, 2017). However, these outcomes do not

423 necessarily match with what youth may want to take away from their sport experiences

424 (Wiersma, 2000). For example, findings from preliminary research indicates that youth

425 athletes may not want to play-up if it prevents them from participating with same-aged

426 friends (Campbell, Bracewell, Blackie, \& Patel, 2018). Anecdotal evidence shows that

427 athletes who play-up may perceive an increased risk of injury due to overtraining or

428 aggressive play from opponents (Moir, 2013). Indeed, this may further existing knowledge

429 concerning Social factors that were limited in this current study. In addition, further

430 longitudinal studies are suggested to identify whether playing-up has long-term benefits

431 towards developing expertise, through exploring transitions from youth level to professional

432 status or by examining how playing-up may accelerate development. Finally, although

433 perhaps applied less commonly, the factors that differentiate those who "play-down" a

434 chronological age group should also be examined. Similarly, the psychosocial implications of

435 playing-down may arguably differ to those who play-up, thus they should be considered as

436 two independent contexts to facilitate an appropriate learning environment for young athletes. 


\section{Conclusion}

438 Findings from this current study support the implementation of the FA Four Corner Model to

439 facilitate a multidisciplinary approach in youth football player development. In the FDP,

440 Technical/Tactical and Social characteristics appeared to differentiate those who play-up

441 compared to those who do not. In the YDP however, there were significant measures

442 representing all four sub-components. Subsequently, it is important that coaches and

443 practitioners consider these holistic factors when deliberating playing youth footballers up a

444 chronological age group within both age phases. Further, coaches and practitioners are

445 encouraged to utilise playing-up as a strategy to facilitate greater individual development,

446 rather than solely focussing on fixed chronological age grouping for elite performance. 
447 Disclosure statement

448 The authors declare that they have no conflict of interest.

\section{Word count}

$450 \quad 5,156$ (excluding Abstract, Tables, and References). 


\section{References}

Abbott, A., \& Collins, D. (2004). Eliminating dichotomy between theory and practice in talent identification and development: Considering the role of psychology. Journal of Sports Sciences, 22(5), 395-408.

Baker, J., Schorer, J., \& Wattie, N. (2018). Compromising talent: Issues in identifying and selecting talent in sport. Quest, 70(1), 48-63.

Barnsley R. H., Thompson, A. H., \& Barnsley, P.E. (1985). Hockey success and birthdate: The relative age effect. Canadian Association of Health, Physical Education and Recreation Journal, 51(1), 23-28.

Baxter-Jones, A. (1995). Growth and development of young athletes: Should competition be age related? Sports Medicine, 20(2), 59-64.

Belling, P. K., Suss, J., \& Ward, P. (2014). Advancing theory and application of cognitive research in sport: Using representative tasks to explain and predict skilled anticipation, decision making, and option-generated behaviour. Psychology of Sport and Exercise, 16(1), 45-59.

Boardley, I. D., \& Kavussanu, M. (2007). Development and validation of the moral disengagement in sport scale. Journal of Sport and Exercise Psychology, 29(5), 608628.

Bradley, B., Johnson, D., Hill, M., McGee, D., Kana-ah, A., Sharpin, C., Sharp, P., Kelly, A. L., Cumming, S. P., \& Malina, R. M. (2019). Bio-banding in academy football: Player's perceptions of a maturity matched tournament. Annals of Human Biology 46(5), 400-408.

Bruner, M. W., \& Benson, A. J. (2018). Evaluating the psychometric properties of the Social Identity Questionnaire for Sport (SIQS). Psychology of Sport and Exercise, 35, 181188.

Buchheit, M., \& Mendez-Villanueva, A. (2014). Effects of age, maturity and body dimensions on match running performance in highly trained under-15 soccer players. Journal of Sports Sciences, 32(13), 1271-1278.

Campbell, E. C., Bracewell, P. J., Blackie, E., \& Patel, A. K. (2018). The impact of Auckland junior rugby weight limits on player retention. Journal of Sport and Health Research, 10(2), 317-326. 
Carling, C., Le Gall, F., \& Malina, R. M. (2012). Body size, skeletal maturity, and functional characteristics of elite academy soccer players on entry between 1992 and 2003. Journal of Sports Science, 30(15), 1683-1693.

Cobley, S., Baker, J., Wattie, N., \& McKenna, J. (2009). Annual age-grouping and athlete development. Sports Medicine, 39(3), 235-256.

Collins, D., \& MacNamara, A. (2017). Making champs and super-champs - Current views, contradictions, and future directions. Frontiers in Psychology, 8, 823.

Côté, J., Bruner, M., Erickson, K., Strachan, L., \& Fraser-Thomas, J. (2010). Athlete Development and Coaching. In C. Cushion \& J. Lyle (Eds.), Sports Coaching: Professionalism and Practice (pp. 63 -78). Amsterdam: Elsevier.

Côté, J., Baker, J., \& Abernethy, B. (2007). Practice and Play in the Development of Sport Expertise. In G. Tenenbaum \& R. C. Eklund (Eds.), Handbook of Sport Psychology ( ${ }^{\text {rd }}$ ed.) (pp. 184-202). Hoboken, NJ: John Wiley and Sons.

Côté, J., Turnnidge, J., Vierimaa, M. (2016). A Personal Assets Approach to Youth Sport. In R. Green \& A. Smith (Eds.), Routledge Handbook of Youth Sport (pp. 243-256). London: Routledge.

Cumming, S. P., Brown, D. J., Mitchell, S., Bunce, J., Hunt, D., Hedges, C., Crane, G., Gross, A., Scott, S., Franklin, E., Breakspear, D., Dennison, L., White, P., Cain, A., Eisenmann, J. C., \& Malina, R. M. (2018). Premier League academy soccer players' experiences of competing in a tournament bio-banded for biological maturation. Journal of Sports Sciences, 36(7), 757-765.

Cumming, S. P., Searle, C., Hemsley, J. K., Haswell, F., Edwards, H., Scott, S., Gross, A., Ryan, D., Lewis, J., White, P., Cain, A., Mitchell, S. B., \& Malina, R. M. (2018). Biological maturation, relative age and self-regulation in male professional academy soccer players: A test of the underdog hypothesis. Psychology of Sport and Exercise, $39,147-153$.

Cumming, S. P., Lloyd, R. S., Oliver, J. L., Eisenmann, J. C., \& Malina, R. M. (2017). Biobanding in sport: Applications to competition, talent identification, and strength and conditioning of youth athletes. Strength \& Conditioning Journal, 39(2), 34-47.

Delorme, N., Chalabaev, A., \& Raspaud, M. (2011). Relative age is associated with sport dropout: Evidence from youth categories of French basketball. Scandinavian Journal of Medicine and Science in Sports, 21(1), 120-128.

Doncaster, G., Medina, D., Drobnic, F., Gómez-Díaz, A. J., \& Unnithan, V. (2020). Appreciating factors beyond the physical in talent identification and development: 
Insights from the FC Barcelona sporting model. Frontiers in Sports and Active Living, $2,91$.

Ericsson, K. A., Krampe, R. T., \& Tesch-Roemer, C. (1993). The role of deliberate practice in the acquisition of expert performance. Psychological Review, 100(3), 363-406.

Ford, P. R., \& Williams, M. A. (2017). Sport Activity in Childhood: Early Specialisation and Diversification. In J. Baker, S. Cobley, J. Schorer, \& N. Wattie (Eds.), Routledge Handbook of Talent Identification and Development in Sport (pp. 117-132). London: Routledge.

Ford, P. R., Ward, P., Hodges, N. J., \& Williams, A. M. (2009). The role of deliberate practice and play in career progression in sport: The early engagement hypothesis. High Ability Studies, 20(1), 65-75.

Gil, S. M., Zabala-Lili, J., Bidaurrazaga-Letona, I., Aduna, B., Lekue, J. A., SantosConcejero, J., \& Granados, C. (2014). Talent identification and selection process of outfield players and goalkeepers in a professional soccer club. Journal of Sports Sciences, 32(20), 1931-1939. 
Ginsburg, R. (2014). Coaching youth lacrosse: The case for not "playing up" [online]. Retrieved from: https://www.uslacrosse.org/blog/coaching-youth-lacrosse-the-casefor-not-\%E2\%80\%9Cplaying-up\%E2\%80\%9D

Gledhill, A., Harwood, C., \& Forsdyke, D. (2017). Psychosocial factors associated with talent development in football: A systematic review. Psychology of Sport and Exercise, 31, 93-112.

Goldman, D. E., Turnnidge, J., Kelly, A. L., de Vos, J., \& Côté, J. (under review). Athlete perceptions of "playing-up" in youth soccer.

Gomez, M., Mitrotasios, M., Armatas, V., \& Lago-Penas, C. (2018). Analysis of playing styles according to team quality and match location in Greek professional soccer. International Journal of Performance Analysis in Sport, 18(6), 986-997.

Gonaus, C., \& Müller, E. (2012). Using physiological data to predict future career progression in 14- to 17-year-old Austrian soccer academy players. Journal of Sports Sciences, 30(15), 1673-1682.

Gouvea, M. A., Cyrino, E. S., Valente-dos-Santos, J., Ribeiro, A., Silva, D. R. P., Ohara, D., Coelho-e-Silva, M. J., \& Ronque, E. (2017). Comparison of skillful vs. less skilled young soccer players on anthropometric, maturation, physical fitness and time of practice. International Journal of Sports Medicine, 38(5), 384-395.

Güllich, A. (2019). "Macro-structure” of developmental participation histories and "microstructure" of practice of German female world-class and national-class football players. Journal of Sports Sciences, 37(12), 1347-1355.

Güllich, A., Kovar, P., Zart, S., \& Reimann, A. (2016). Sport activities differentiating matchplay improvement in elite youth footballers - a 2-year longitudinal study. Journal of Sports Sciences, 35(3), 207-215.

Hancock, D. J., Ste-Marie, D. M., \& Young, B. W. (2013). Coach selections and the relative age effect in male youth ice hockey. Research Quarterly for Exercise and Sport, 84(1), 126-130.

Harwood, C., Drew, A., \& Knight, C. J. (2010). Parental stressors in professional youth football academies: A qualitative investigation of specialising stage parents. Qualitative Research in Sport and Exercise, 2(1), 39-55.

Helsen, W. F., Starkes, J. L., \& Van Winckel, J. (1998). The influence of relative age on success and dropout in male soccer players. American Journal of Human Biology, 10(6), 791-798. 
Hendry, D. T., \& Hodges, N. J. (2018). Early majority engagement pathway best defines transitions from youth to adult elite men's soccer in the UK: A three time-point retrospective and prospective study. Psychology of Sport and Exercise, 36, 81-89.

Hendry, D. T., Crocker, P. R. E., Williams, M. A., \& Hodges, N. J. Tracking and comparing self-determined motivation in elite youth soccer: Influences of developmental activities, age, and skill. Frontiers in Psychology, 10, 304.

Hendry, D. T., Williams, A. M., \& Hodges, N. J. (2018). Coach ratings of skills and their relations to practice, play and successful transitions from youth-elite to adultprofessional status in soccer. Journal of Sports Sciences, 36(17), 2009-2017.

Hill, A. P., Hall, H. K., Appleton, P. R., \& Kozub, S. A. (2008). Perfectionism and burnout in junior elite soccer players: The mediating influence of unconditional self-acceptance. Psychology of Sport and Exercise, 9(5), 630-644.

Hornig, M., Aust, F., \& Güllich, A. (2016). Practice and play in the development of German top-level professional football players. European Journal of Sport Science, 16(1), 96105.

Huijgen, B. C. H., Elferink-Gemser, M. T., Lemmink, K. A. P. M., \& Visscher, C. (2014). Multidimensional performance characteristics in selected and deselected talented soccer players. European Journal of Sport Science, 14(1), 2-10.

Kavussanu, M., White, S. A., Jowett, S., \& England, S. (2011). Elite and non-elite male footballers differ in goal orientation and perceptions of parental climate. International Journal of Sport and Exercise Psychology, 9(3), 284-290.

Kavussanu, M., \& Boardley, I. D. (2009). The prosocial and antisocial behavior in sport scale. Journal of Sport \& Exercise Psychology, 31(1), 97-117.

Kelly, A. L., \& Williams, C. A. (2020). Physical characteristics and the talent identification and development processes in male youth soccer: A narrative review. Strength and Conditioning Journal [ePub ahead of print].

Kelly, A. L., Wilson, M. R., Gough, L. A., Knapman, H., Morgan, P., Cole, M., Jackson, D. T., \& Williams, C. A. (2020). A longitudinal investigation into the relative age effect in an English professional football club: The 'underdog hypothesis'. Science and Medicine in Football, 4(2), 111-118.

Kelly, A. L., Wilson, M. R., Jackson, D. T., Turnnidge, J., \& Williams, C. A. (2020). Speed of thought and speed: Examining perceptual-cognitive expertise and physical performance in an English football academy. Journal of Science in Sport and Exercise [ePub ahead of print]. 
616 Kelly, A. L., Wilson, M. R., Jackson, D. T., \& Williams, C. A. (2020). Technical testing and

617

618

619

620

621

622

623

624

625

626

627

628

629

630

631

632

633

634

635

636

637

638

639

640

641

642

643

644

645

646

647 match analysis statistics as part of the talent development process in an English football academy. International Journal of Performance Analysis in Sport [ePub ahead of print].

Kelly, A. L., Wilson, M. R., \& Williams, C. A. (2018). Developing a football-specific talent identification and development profiling concept - The Locking Wheel Nut Model. Applied Coaching Research Journal, 2, 32-41.

Khamis, H. J., \& Roche, A. F. (1994). Predicting adult stature without using skeletal age: The Khamis-Roche method. Pediatrics, 94(1), 504-507.

Kulik, J. A. (2004). Meta-Analytic Studies of Acceleration. In N. Colangelo, S. G. Assouline, \& M. U. M. Gross (Eds.), A Nation Deceived: How Schools Hold Back America's Brightest Students (2 ${ }^{\text {nd }}$ ed.) (pp. 13-22). Reno, NV: Educators Guild Newsletter.

Lefebvre, J. S., Evans, M. B., Turnnidge, J., Gainforth, H. L., \& Côté, J. (2016). Describing and classifying coach development programmes: A synthesis of empirical research and applied practice. International Journal of Sports Science \& Coaching, 11(6), 887-899.

Liu, H., Hopkins, W. G., \& Gomez, M. A. (2016). Modelling relationships between match events and match outcome in elite football. European Journal of Sport Science, 16(5), $516-525$.

Lloyd, R. S., \& Oliver, J. L. (2012). The youth physical development model. Strength and Conditioning Journal, 34(3), 61-72.

MacNamara, A., \& Collins, D. (2011). Development and initial validation of the Psychological Characteristics of Developing Excellence Questionnaire. Journal of Sports Science, 29(12), 1273-1286.

MacNamara, A., \& Collins, D. (2013). Do mental skills make champions? Examining the discriminant function of the psychological characteristics of developing excellence questionnaire. Journal of Sports Sciences, 31(7), 736-744.

Malina, R. M. (2010). Early sport specialization: Roots, effectiveness, risks. Current Sports Medicine Reports, 9(6), 364-371.

Malina, R. M., Cumming, S. P., Rogol, A. D., Coelho-e-Silva, M. J., Figueiredo, A. J., Konarski, J. M., \& Kozieł, S. M. (2019). Bio-banding in youth sports: Background, concept, and application. Sports Medicine, 49(774), 1671-1685. 
Malina, R. M., Rogol, A. D., Cumming, S. P., Coelho-e-Silva, M. J., \& Figueiredo, A. J. (2015). Biological maturation of youth athletes: Assessment and implications. British Journal of Sports Medicine, 49(13), 852-859.

Memmert, D., Baker, J., \& Bertsch, C. (2010). Play and practice in the development of sport- specific creativity in team ball sports. High Ability Studies, 21(1), 3-18.

Meylan, C., Cronin, J., Oliver, J., \& Hughes, M. (2010). Talent identification in soccer: The role of maturity status on physical, physiological and technical characteristics. International Journal of Sports Science \& Coaching, 5(4), 571-592.

Moir, J. (2013). Size does matter, 71 kg 10-year-old gets told [online]. Retrieved from: http://www.stuff.co.nz/sport/rugby/8476408/Siz\%20e-does-matter-71kg-10-year-oldgets-told

Morgan, S. J., Pullon, S. R. H., Macdonald, L. M., McKinlay, E. M., \& Gray, B. V. (2017). Case study observational research: A framework for conducting case study research where observation data are the focus. Qualitative Health Research, 27(7), 1060-1068.

Musch, J., \& Grondin, S. (2001). Unequal competition as an impediment to personal development: A review of the relative age effect in sport. Developmental Review, 21(2), 147-167.

Neihart, M. (2007). The socioaffective impact of acceleration and ability grouping: Recommendations for best practice. Gifted Child Quarterly, 51(4), 330-341.

O'Sullivan, J. (2017). Should my child play up? The do's and don'ts of moving kids to older age groups [online]. Retrieved from: https://changingthegameproject.com/child-playdos-donts-moving-kids-older-age-groups/

Pearson, D. T., Naughton, G. A., \& Torode, M. (2006). Predictability of physiological testing and the role of maturation in talent identification for adolescent team sports. Journal of Science and Medicine in Sport, 9(4), 277-287.

Piggott, B., Müller, S., Chivers, P., Papaluca, C., \& Hoyne, G. (2019) Is sports science answering the call for interdisciplinary research? A systematic review. European Journal of Sport Science, 19(3), 267-286.

Rampinini, E., Impellizzeri, F. M., Castagna, C., Couus, A. J., \& Wisloff, U. (2009). Technical performance during soccer matches of the Italian Serie A league: Effect of fatigue and competitive level. Journal of Science and Medicine in Sport, 12(1), 227233.

Renshaw, I., Oldham, A., \& Bawden, M. (2012). Nonlinear pedagogy underpins intrinsic motivation in sports coaching. Open Sports Sciences Journal, 5(1), 88-99. 
682

683

684

685

686

687

688

689

690

691

692

693

694

695

696

697

698

699

700

701

702

703

704

705

706

707

708

709

710

711

712

713

Roca, A., Williams, A. M., \& Ford, P. R. (2012). Developmental activities and the acquisition of superior anticipation and decision making in soccer players. Journal of Sports Sciences, 30(15), 1643-1652.

Sarmento, H., Anguera, M. T., Pereira, A., \& Araujo, D. (2018). Talent identification and development in male football: A systematic review. Sports Medicine, 48(4), 907-931.

Sherar, L. B., Baxter-Jones, A. D., Faulkner, R. A., \& Russell, K. W. (2007). Do physical maturity and birth date predict talent in male youth ice hockey players? Journal of Sports Sciences, 25(8), 879-886.

Steenbergen-Hu, S., Makel, M. C., \& Olszewski-Kubilius, P. (2016). What one hundred years of research says about the effects of ability grouping and acceleration on $\mathrm{K}-12$ students' academic achievement: Findings of two second-order meta-analyses. Review of Educational Research, 86(4), 849-899.

Steenbergen-Hu, S., \& Moon, S. M. (2011). The effects of acceleration on high-ability learners: A meta-analysis. Gifted Child Quarterly, 55(1), 39-53.

Taylor, J., \& Collins, D. (2019). Shoulda, coulda, didnae - Why don't high-potential players make it? The Sport Psychologist 33(2), 85-96.

The Football Association. (2014). England DNA [online]. Retrieved from: http://www.thefa.com/news/2014/dec/04/england-dna-launch

The Football Association. (2019). The playing and coaching philosophy of England teams [online]. Retrieved from: http://www.thefa.com/learning/england-dna

Tieso, C. (2005). The effects of grouping practices and curricular adjustments on achievement. Journal for the Education of the Gifted, 29(1), 60-89.

Towlson, C., Cope, E., Perry, J. L., Court, D., \& Levett, N. (2019). Practitioners' multidisciplinary perspectives of soccer talent according to phase of development and playing position. International Journal of Sports Science \& Coaching, 14(4), 528540.

U.S. Soccer. (2011). Playing up: Better competition means faster development for young academy players [online]. Retrieved from: https://www.ussoccer.com/stories/2014/03/17/12/46/playing-up-means-fasterdevelopment

Ullrich-French, S., \& Smith, A. L. (2009). Social and motivational predictors of continued youth sport participation. Psychology of Sport and Exercise, 10(1), 87-95. 
Vaeyens, R., Malina, R. M., Janssens, M., Van Reterghem, B., Bourgois, J., Vrijens, J., \& Philippaerts, R. M. (2006). A multidisciplinary selection model for youth soccer: The Ghent Youth Soccer Project. British Journal of Sports Medicine, 40(11), 928-934.

Vygotsky, L. S. (1978). Mind in society: The development of higher psychological processes. Cambridge, MA: Harvard University Press.

Wattie N., \& Baker J. (2018). An Uneven Playing Field: Talent Identification Systems and the Perpetuation of Participation Biases in High Performance Sport. In R. Dionigi \& M. Gard (Eds.), Sport and Physical Activity across the Lifespan (pp. 117-133). London: Palgrave Macmillan.

Wattie, N., Cobley, S., \& Baker, J. (2008). Towards a unified understanding of relative age effects. Journal of Sports Sciences, 26(13), 1403-1409.

Wiersma, L. D. (2000). Risks and benefits of youth sport specialization: Perspectives and recommendations. Pediatric Exercise Science, 12(1), 13-22.

Williams, A. M., \& Drust, B. (2012). Contemporary perspectives on talent identification and development in soccer. Journal of Sport Sciences, 30(15), 1571-1572. performance indicators indicative of team quality in the soccer Chinese super league. Research in Sports Medicine, 26(2), 158-167. 
733 Table 1. Technical/Tactical variable descriptive statistics, independent $t$-test results, and 734 univariate regression models.

735 Table 2. Physical variable descriptive statistics, independent $t$-test results, and univariate 736 regression models.

737 Table 3. Psychological variable descriptive statistics, independent $t$-test results, and 738 univariate regression models.

739 Table 4. Social variable descriptive statistics, independent $t$-test results, and univariate 740 regression models.

741 Table 5. Multivariate logistic regression across the four corners. 